NoTICE

PORTIONS OF THIS FEF? T ARE ILLEGIBLE. It

has been reproduced from the best available

copy to pormit the broadest posslble avall.

ability.
SLAC-SI1- - 3A-4

DE84 009414

\title{
STABILITY OF KLYSTRON OPERATION AS A FUNCTION OF INPUT PARAMETERS*
}

\author{
AMARJIT SINGH \\ Central Electronics Engineering Reacarch Institute \\ Pilani, Rajasthan, India \\ and \\ Klyatron Department, Stanford Linear Accelerator Center \\ Stanford University, Stanjord, California 94305 \\ Gerhard T. KonRad and Charles Griffin \\ Klystron/Vacuum Department, Stanford Linear Accelerctor Center \\ Stanford Universily, Stanford, California $9\{305$
}

\begin{abstract}
Instabilities in the speration of a high-power multicavity klystron have been studied as a function of various input parameters. Amoag these, the focusing magnetic field, if input power and tuning of the second harmonic cavity were observed to have a striking effect in deciding the regions of unstable operation.

One region of instability could be identified with a value of magnetic field corresponding to cyclotron resonance, at the operating frequency. The magnetic field value in the region of the input end, and the second harmonic cavity, was found to have a more decisive influence on stability, than the magnetic field at the output end.

A hysteresis effect has been associated with the instabilities. This could be explained in terms of multipactor phenomena.

These observations indicate, among other things, that in designing new tubes, it might be desirable that the operating magnetic field stay well away from cy, clotron resonance conditions, especially in the gun segion, and the cavities at the input end. The experimental techniques can be used for optimizing the operating conditions of existing tubes.

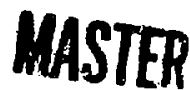

- Work supported by the Department of Energy, contract DE-AC03-76SF00515.

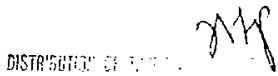




\section{Introduction}

In high power multicavity klystrons an axisl magnetic field is used in order to keep the electron beam focused in its progression through the sequence of cavities. The parameters most commonly watched are the linkage of magnetic flux with the cathode and the ratio of the maguetic field in the rest of the tube to the Brillouin field.

These are important parameters in the static design of the electron gun and the focusing properties of the electron beam. ${ }^{1}$ The above mentioned ratio has also been used as the parameter defining the magnetic field in dynamic studies which consider the lateral as well as longitudinai motion of electrons. ${ }^{2,3}$

In tha case of rising-sun magnetrons, which have a zero order component if feld present along with the $\pi$ mode, it is known that the efficiency of operation drops at magnetic fields which correspond to cyclotron resonance. The cyclotron resonance there interferes with the normal trajectories of electrons moving in the interaction space.

In the case of high power klystrons, lateral movement becomes quite significant as a result of bunching and of space charge forces. It may therefore be expected that any independent cumulative effect, such as cyclotron resonance, may have a significant impact on the trajectories and interfere with normal operations.

Another phenomenon which can cause variations in power output as a function of the magnetizing feld is that of multipactor. It occurs when the de and if field ure such that electrons strike one or more surfaces repeatedly while thay gain energy in traneit and release secondary electrons at each impact. If the secondary emission coefficient is greater than one for the given energy of the arriving electrons, the oscillating space charge builds up rapidly. ${ }^{6}$ This space charge has the effect of inducing additional if currents into the cavity. This has the effect of tuning the cavity and also of absorbing 


\section{DISCLAIMER}

This report was prepared as an account of work sponsored by an agency of the United States Government. Neither the United States Government nor any agency thereof, nor any of their employees, makes any warranty, express or implied, or assumes any legal liability or responsibility for the accuracy, completeness, or usefuiness of any information, apparatus, product, or process disclosed, or represents that its use would not infringe privately owned rights. Reference herein to any specific commercial product, process, or service by trade name, trademark, manufacturer, or otherwise does not necessarily constitute or imply its endorsement, recommendation, of favoring by the United States Government or any agency thereof. The views and opinions of authors expressed herein do not necessarily state or reflect those of the United States Government or any agency thereof. 
some of the power. Different modes of multipactor exist in which there is an integral relationship between the transit time and half the period of if oscillation.

An objective of this investigation was to gain a better understanding of both these types of phenomena, which can interfere with clean operation at higher power levels.

The klystron studied had been developed at the Stanford Linear Accelerator Center $^{6}$ for use in the positron and electron project (PEP). Its magnetic field is generated by a set of ten coils. Current in these could be varied collectively or individually. This provided gexibility in controlling the magnetic field and its profile. A cross-section of the tube is shown in Fig. 1.

It is a CW tube with a power output of $500 \mathrm{KW}$. Efficiency being an important consideration, a second harmonic cavity has been incorporated into the design, as cavity number three, out of a total of five cavities.

In the experimental setup, an $\mathrm{X}-\mathrm{Y}$ recorder was used in conjunction with a variety of messuring instruments to draw a series of curves, ccvering a wide range of operating parameters. The operation was studied as a function of magnetic feld, operating voltage, if drive level, and tuning of the second harmonic cavity, et cetera, which served as parameters for the curves.

As the if drive power fed ixto the input cavity was progressively increased, welldefined thresholds of instabilities were observed at certain values of magnetic field. Studies were made in which magnetic field was left constant in certain regions and varied in others, so as to localize the causes of the observed effects.

There are pick-up prohes located in the different cavities. The output from these was also studied as a function of the magnetic ficld. This helps to correlate the observations with the phenomena occurring in the individual cavities.

Simultaneuus measurements of power output and residudi pressure inside the tube were made while varying the focusing field. Correlations with instabilities were studied. 


\section{The Experiental Setup}

The measurement system has provisions for determining thermal dissipation in different parts of the tube. These cover a variety of overload situations, or overheating of various parts, such as cavities, collector, et cetera.

The if power is measured by thermistor-bridge type instrumeits, which can be connected to different probes. There is also a calorimetric measurement of heat dissipation separately in the input cavity, the output cavity (together with the output window and the drift space between the output cavity) and the collector. The initial measurements were made with the calorimetric setup. The later sets wore taken with the belp of a thermistor-bridge instrument whose recorder output was connected to theY-axis of an $\mathrm{X}-\mathrm{Y}$ zecorder. The $\mathrm{X}$-axis was fed from a resistor in the path of the current flowing through those coils whose field was being scanned through a range of values. This made it possible to scan through the field values in a relatively short period each time. Hysteresis effects, as between rising and falling values of feld current, could be easily identified. While calibration of values was done occasionaily, it was not done at the start of every set of curves. This does not affect the overall nature of the phenomena observed in a wide ranging survey, which covers a matrix of many variables indicated above.

Frequency spectra w.re recorded at specific points, especially when there was a change crer from one kind of behavior to another. Output from the second harmonic cavity was also observed on a spectrum analyzer. Time variations in output were recorded, espen:ally where there was a region of instability. Occasionally checks were made, by momentarily shutting of the heater supply so as to make a distinction between bum originating from the flament supply and fuctuations due to phenomena accurring in the interaction space. 
The magnetic field bad earlier been plotted for the given set of coils connected in series. A typical distribution is shown in Fig. 2. The magnetic field under different experimental conditions was estimated from those measurements by interpolations. It is to be noted that at a given value of current passing through all the coils, the magnetic field at all points is not the same. In particular, there is a large variation in the region of the cathode and at the near end of the sollector. Consequently the cyclotron resonance value of magnetic field would be given for different regions with somewhat different values of current. This difference could be large for the end regions. The magnetic field in the median plane of each coil is also influenced by the current in the neighboring coils, especially the adjacent ones.

In the experiments the current through coils number three to ten was varied in different combinations or altogether. The current through the bucking coils, (i.e., coils number one and two, near the cathode region) was however kept at a constant value so as to ensure that as far as the beam formation in the gun region is concerned, it might not be disturbed.

There is spillover of the field due to the bucking coils into the region of cavities number one and two. As a result of this the magnetic field in the region of cavities one and two was not proportional to the çurrent in the other coils, namely three, four, five, et cetera. The calculations of the magnetic field were suitably adjusted in order to take into account this constant magnetic field

Cyclotrun resonance depends upon the effective mass of the electrons, and consequently on the anode voltage $\left(V_{0}\right)$. From the foregoing it is seen that th: value of magnetic field required for cyclotron resonance, and that of the focusing $\mathrm{c}$ Irrent, would be depesdent on some of the other parameters, such as anode voltage, location of resonance region in the tube, current distribution through the coils, et cetera. 
However, for most of the measurements, the relativistic correction was small and the current through coils numbers three to ten $\left(I_{m a g}\right)$ was used as an independent variable. In this case the cyclotron resonance was estimated to occur at $I_{m a g}=16$ A for the region of cavity number one, assuming the rest mass for the electrons.

In order not to overstress the tube, when the magoetic feld and input il drive power $\left(\boldsymbol{P}_{i n}\right)$ were varied over wide ranges, the anode voltage was initially kept nt lower values than the normal operating value of $\mathrm{BO} K \mathrm{KV}$. Instabilities were also more prominent at some of the lower values. Later on data was also taken at $57 \mathrm{KV}$ with a reduced range for the other variables.

\section{Experimental Results}

The operation of the klystrons depends upon a matrix of input parameters. The variable parameters were chosen successively so as to study their effects in conjunction with other parameters of interest. The first set of data refer to tbe case where all the coils except one, two were connected ir series. Subsequently, the currents were varied independently, so as to localize the effects of resonances.

\subsection{REGIONS OF REDUCED POWER OUTPUT}

In the first experiments, where sharp changes in output were observed as a result of variation of current $\left(I_{m a g}\right)$ in coils number three to ten, the plotting of different parameters was done point by point. In this case, apart from the power output, the rise of temperature, $\Delta T$, of the cooling fluid going to the collector, and separately into the last drift tube and the output cavity, was also plotted. All these curves are shown in Fig. 3.

It is noticed that there is a sharp reduction in the output power at $15.6 \mathrm{~A}$ and an upswing at $17 \mathrm{~A}$ as the current $I_{\text {mag }}$ is raised. Correspondingly, the dissipation in 
the collector rises in this region. The $\Delta T$ for the drift tube region and that for the output cavity area are not affecied to the same extent. (It is to be recalled that wittin experimental error a current of $16 \mathrm{~A}$ through the coils corresponds to a magnetic field at the input cavity which would give cyclotron resonance at the operation frequency).

Apart from this region where there are sharp changes, there is also another one at lower current in the range of $11.5 \mathrm{~A}$. Here, as the current rises beyond $11.5 \mathrm{~A}$ the power output suddenly falls and also the collector temperature rises. Below this value of current the heating of the output cavity and the nearby tube is considerably higher as shown by the $\Delta T_{r f}$ curve. The dip in power is at a current approximately two thirds of tbe current for the dip mentioned previously. This additional dip could be attributed to a different mude of resonanee in multipactor phenomena.

\subsection{Hrsteresis Phenomena}

In Fig. 4 the power output from the klystron is plotted against the current through coils number three to ten, with anode voltage as parameter at. $34 \mathrm{KV}$ and $38 \mathrm{KV}$. Ln these and subsequent figures the plotting was done semiautcmatically on an X-Y recorder, as explained earlier. It is seen that in the vicinity of 16 A there is a dip which has the following characteristics: between 16 and $16.25 \mathrm{~A}$ the curves for increasing and decreasing $I_{\text {mag }}$ coincide; however, hysteresis is present between 16.25 and $17.6 \mathrm{~A}$. The changeover point at $16.25 \mathrm{~A}$ is presumably the cyclotron resonance point.

\subsection{PICKuP from Cavities}

The curves in Fig. 5 show the variation of power output as well as the pickup Irom the probe in the second harmonic cavity (number three) versus the current $I_{\text {mag }}$ through coils number three to ten. The figure also shows that the peak between 13.2 and $14.5 \mathrm{~A}$ does not show up in the pickup from the cavity number three, which indicates that this resonance is due to phenomena taking place in some other region. 
It is seen also that the variation of the pickup from the probe in the current range 16.5 to $18.5 \mathrm{~A}$ is similar to the shape of the curve shown for a similar pickup versus resonance frequency of second harmonic cavity. ${ }^{\circ}$ Figure 6, taken 'rom Ref. B, shows the curve as well as the variation of power output versus mechadisal tuning. The similarity of shape of the pickup curve points to a phenomenon of electronic tuning, such as by space charge.

Pickup from cavities number one to four (cavity five does not have a sampling probe) is shown in Fig. 7 as a function of $I_{\text {mag }}$. In this it is noticad that the resonance in the region of $13.5 \mathrm{~A}$ shows up in cavities number two and four and not in the second harmonic cavity. Furthermore, it is seen that a hysteresiz phenomenon is observed in the pickup from cavities number one, two and four, as well. In the region of $I_{m a g}=17 \mathrm{~A}$ it is seen that the pickup is higher on the increasing $I_{m a g}$ curve than for the decreasing $I_{m a g}$ curve. These changes correspond to changes in opposite direction as regards power output. The reverse is true for the case of the hysteresis observed in the region of $I_{m a g}=12 \mathrm{~A}$. The pickup in the second harmonic cavity is sharply peaked in the region of $17 \mathrm{~A}$ (as also seen in Fig. 5), whereas that for the other cavities has a flat peak.

\subsection{Effects of Retuning the Second Harmonic Cavity}

Figure 8 shows the curves for power output versus $I_{m a g}$ when the second harnonic cavity has been retuned to a frequency of $896.508 \mathrm{MHz}$; that is, to a lower than normal frequency. In this case it is observed that on the curve for a decreasing value of $I_{\text {mag }}$, in the region of $17 \mathrm{~A}$, the power output stays nearly constant at a level higher than for rising $I_{\text {mag }}$. At a critical value it falls suddenly. The value of $I_{\text {mag }}$ at this sharp transition point is slightly higher for the higher values of anode voltage.

The ratio of the relativistic mass at $38 \mathrm{KV}$ versus $32 \mathrm{KV}$ is 1.015 , and within experimental error, it is also the ratio of the above mentioned eritical values of $I_{m a g}$ at 
the two voltages. This agreement between the two ratios is indicative of the possibility that relativistic effects are showing up in the sharply defined resonances.

Figure 8 shows the power output versus $I_{\text {mag }}$ at different values of anode voltage, with the sesond harmonic cavity tuned to a frequency of $708.132 \mathrm{MHz}$ which is higher than the normal value. In this case it is seen that in the region $l_{\text {mag }}=17 \mathrm{~A}$ on the upward going curve, the power output falls practically to zero for all the anode voltages. Furthermore, on the return path the power output rises above the value that it reached at higher values of focusing current. Also, there is a dip is the output at $16 \mathrm{~A}$. Below $15 \mathrm{~A}$ there is very little hysteresis. The region around $13 \mathrm{~A}$ shows a pronounced peak.

The question arises as to why there is bysteresis in certain regions of $I_{m o g}$ and not in others, and what is the reason for the kind of changes observed around $16 \mathrm{~A}$. A possible explanation is that in the region of hysteresis there is a different multipactor mode in the two branches of the curve in the sense that the transit time is a different multiple of $T / 2$. It is also conceivable that as multipactor starts in any given mode, depending upon the value of the magnetic field at which if starts, it would tend to continue in the mode because the bunches baving been formed in a certain phase and then having been multiplied in that phase, they will continue in that very phase.

In the vicinity of $16 \mathrm{~A}$ which is also the region of cyclotron resonance, it is conceiv. able that below the resonance magnetic field the phase of the multipactor is different from what it is above this magnetic field.

Another possibility is the presence of space cbarge, which can give an additional field superimposed on thri zaused by the cavity and the normal beam. The levels of resirnal gases can be another is:ue to consider, as has been done in a subsequent section. 


\subsection{THRESHOLd For INPUT RF DRIVs. POWER}

Figure 10 gives two sets of curves which show tie variation of power output as a function of current through coils number three to ten at different values of drive fower. It is seen that the threshold is very sharp for the dip in power output that appears in the vicinity of $I_{\text {mag }}=16 \mathrm{~A}$. While for $5.7 \mathrm{~W}$ drive there is no dip in power in the region between $15.7 \mathrm{~A}$ and $17 \mathrm{~A}$ at $5.8 \mathrm{~W}$ drive it suddenly appears (in the figure the curve has been given for $\mathrm{B.0} \mathrm{W}$ drive for convenience in showing sejarate linesj.

The sharpness of threshold could be explained by the bypothesis that there is multipactor in this region, which reqL ires the electrons to strike the surface with a certain minimum voltage so as to give a secondary emission coefficient greater than one.

It is seen that in this curve the hysteresis in the region 11.4 to $12 \mathrm{~A}$ is of opposite nature to the one seen between 15.7 and $18.7 \mathrm{~A}$. In other words, the sutput power is higher on the upward curve in the former case and on the downward curve in the latter case. This ciuld also be attributed to the different modes of multipactor in the two cases. Furthermore, at power drive levels of 2 to $3 \mathrm{~W}$, the power output level is fairly constant throughout the ranje of variation from 11 to $20 \mathrm{~A}$, whereas when the power output goes to $4 \mathrm{~W}$ and above, there is a trough between 11.75 and $17 \mathrm{~A}$.

This would indicate that there is a very broad resonance with a threshold between 3 and $4 \mathrm{~W}$ of drive which creates this trough and also that there are other resonances which are associated with the region 16 to $17 \mathrm{~A}$ for which the threshold lies at $5.75 \mathrm{~W}$ drive level.

In one set of experiments the threshold drive level for introducing the instability in the region of $I_{m a g}=16 \mathrm{~A}$ was studied as a function of .ode voltage. As seen in Fig. 11, the drive threshold decreases with increasing voltage. It is $5.2 \mathrm{~W}$ for $55 \mathrm{KV}$ and $6.6 \mathrm{~W}$ fo: $40 \mathrm{KV}$ anode voltage. 
Figure 12 shows the power output versus $I_{\text {mag }}$ right nesr the threshold for an anode voltage of $45 \mathrm{KV}$. It is seen that on the upward swing there is a two-peak resonance curve between 15.5 and $17 \mathrm{~A}$, whereas on the return path this variation is smoothed out. (There is a transition also at $18 \mathrm{~A}$.) This would seem to indicate that on the increasing $I_{m a y}$ curve there are sharp changes in phase of the perturbing space charge cloud as one goes from magnetic fields below cyclotron resonance to higher ones. These different. phases could be for multipactor space charge or for the perturbation on the main electron beam. For the decreasing $I_{\text {mag }}$ curve a different multipactor mode is assumed. The residual pressure is also higher as shown anbsequently.

\subsection{REPRODUCIBILITY OF CURVES}

In order to see the reproducibility of the curves and of the transition points, curves were redrawn on the same chart in different runs. Figure 13 shows two sets of such curves for $V_{0}=57 \mathrm{KV}$. It is seen that the curves and transitions are fairly reproducible. This is particularly true in the region of $I_{\text {mag }}=16 \mathrm{~A}$, which corresponds to cyclotron resonance. This would indicate that the phenomena are precisely controlled at this value of magnetic field by cyclotron resonance. This shows that the associated phenomena are precisely determined by electron beam interaction or by multipactor. Any changes caused by phenomena such as release of gases would have tended to be less sharp and mor - variable from run to run, depending upon rate of change of $I_{\text {may }}$.

- Small variations among sets of curves at $\boldsymbol{I}_{m a g}$ greater than $18 \mathrm{~A}$ could be attributed to such effects. There are two peaks and a trough as in the case of Fig. 12. in the region 15.5 to $17.5 \mathrm{~A}$. There is also an additional pisk at $19.75 \mathrm{~A}$ and other troughs at 21 and at $26.25 \mathrm{~A}$.

Figure 14 shows the power output versus $I_{\text {mog }}$ for different values of drive power to considerably higher levels, namely from $10 \mathrm{~W}$ to $24 \mathrm{~W}$. It is seen that as one goes to higher drive power levcls, the troughs in the power output widen. Also more than one 
trough having different hysteresis curves appear at higher drive levels. These could be attributed to different modes of multipactor; however, in the region from 16 to $16.5 \mathrm{~A}$ all of the curves nearly coincide both on the upward and the downward swing of $\boldsymbol{I}_{\text {mag }}$ for all values of input drive power. This again is the ref,ion of $I_{\operatorname{mag}}$ which corresponds to the field fo: cyclotron resonance.

\subsection{Localized Variation of Magnetic Field}

Figure 15 shows variation in power output when current in coils three, four, five and six is kept constant, and that in coils seven, eight, nine and ten is varied. It is seen that the variations in $P_{0}$ are relatively small. This is indicative of the fact that the phenomena causing sudden changes with focusing current are lying essentially near the input end of the tube.

Figure 16 shows the power output when current in coils seven to ten is kept fixed at $20 \mathrm{~A}$ and that in coils three, four, five and six is varied.

The input drive level is set at $5 \mathrm{~W}, 10 \mathrm{~W}$ and $15 \mathrm{~W}$, respectively. It is seen that at $5 \mathbf{W}$ there are no striking changes, except a general rise in $\boldsymbol{P}_{\mathbf{0}}$, as the focusing current rises. There is also no hysteresis. With higher levels of drive, a trough appears above 16.5 A, whose width increases with drive level. Hysteresis also appears around $24 \mathrm{~A}$. Comparing these data with those of the previous figures confirms that the cyclotron and multipack.r resonances are having their major influence in the regions of cavities number one, two and three.

Effects of varying the current in coil number three, $\left(I_{3}\right)$, which is over cavity number one, are given in Fig. 17. The curren: in coils number one and two is fixed at $17 \mathrm{~A}$, the current in coil number three is varied and that in coils number four to ten is fixed at $20 \mathrm{~A}$. The $V_{0}$ is $55 \mathrm{KV}$. In the case of rising $I_{3}$ the power output is influenced by the variation in $I_{3}$. It falls to very small values in the range of 16.5 to $23 \mathrm{~A}$. This points to the possibility that once multipactor starts in cavity number one, it tends to 
persist. For $I_{3}$ decreasing from $26 \mathrm{~A}$ the $P_{0}$ remains high down to $18 \mathrm{~A}$, indicating a substantial hysteresis. There is a sharp resonance at the point $16.5 \mathrm{~A}$ for both rising and falling curves for $I_{3}$. This is the region of cyclotron resonance.

Such a wide range of $I_{3}$, at which the power goes down, was not however observed when current in all coils other than number 3 was fixed at $20 \mathrm{~A}$ and $V_{0}$ was $50 \mathrm{KV}$. This indicates that the phenomenon observed in Fig. 17 was probably due to cyclotron resonance in cavity number one as well as the gun region, as a current of $17 \mathrm{~A}$ in coils number one and two, would be conducive to such a resonance.

\subsection{Variation of Pressure in the Tube as a Function of OPERATINg Parameters}

Since one expects perturbations in the beam due to the phenomena which are being studied, it was considered desirable to observe the variations in pressure witk: variation of the focus current. This was made possible by the fact that he tube has a sputter-ion pump aiready sealed on, which also gives an indication of the pressure.

Figure 18 shows curves of power output as well as of pressure variations, as functions of focus current. The anode voltage was set at $50 \mathrm{KV}$ and input drive power at $12 \mathrm{~W}$. It is seen that for a rising value of $I_{\text {mag, }}$ the changes in pressure follow fairly closely the changes in the power output up to $17 \mathrm{~A}$. Beyond that, gasses released at the transition point at $17 \mathrm{~A}$ are progressively pumped out while the power output stays bigb.

By contrast, for the c'rve for fecreasing value of $I_{\text {mag }}$ the rise in pressure occurs at the region where the power level falls. Furthermore, rise in pressure occurs at a slight,ly lower value of $I_{\text {mag }}(i . e ., 16.6 \mathrm{~A}$ ) than the fall in power (at $17.0 \mathrm{~A}$ ). This indicates that the rise in pressure is an effect, and not a cause. The likely causes could be a change in the beam profile and its increased interception, or the start of a multipactor mode. 
From the nature of the relationship between power output curve and the pressure variations one can deduce that the release in gasses on the upward curve of $l_{\text {mag }}$ oceurs in the output region, as the increased pressure coincides with increased power output, increased bunching and lateral defocusing. By the same argument, on the decreasing $I_{m a g}$ curve, the decrease in power output could be attributed to perturbing phenomena occurring in the earlier cavities, causing a decrease in bunching and a deerease of power output (accompanied by release of residual gases and incrcase of pressure).

Plotted in Fig. 19 are similar curves for power output as well at the pressure, with variation of focus current through coils number three to ten at an anode voltage of 60 $\mathrm{KV}$ and input power of $10 \mathrm{~W}$. In this case the pressure variation generally follows the power output curve. There is also very little hysteresis. (This is indicative of the fact that at the higher voltages near the normal operating voltage there is less perturbation of the beam profile due to cyclotron resonance or multipactor).

Observations of pressure were also taken keeping the input value and focus current constant and varying the anode voltage. It was seen that the rise in pressure was sharply peaked at certain voltages. These were at 37,40 and $43 \mathrm{KV}$.

\subsection{FrequenCy SPECTRA in RF ENVELOPES}

The spectra and rf envelopes were studied especially where transitions were taking place. A few representative types of behavior are shown in Figs, 20 and 21 . In these figures a sequence is seen going from a clean spectral line to the appearance of additional side bands at the points of inst.bbility. These side bands as well as oscillations in the time domain increase with increased drive power. This ultimately leads to an unstable operation and relaxation oscillations. 


\section{Discuseion of Results}

The operation of a CW high power klystron has been studied as a function of the variation of focusing magnetic field along the axis over a wide range of parameters. The changes can be attributed to cyclotron resonance, and to the influence of magnetic field on multipactor phenomena.

It is seen that under certain conditions there can be a sharp drop in power output and a corresponding increase in the collector dissipation. The perturbations have a threshold of input drive power which tends to be very sharp. The threshold level of input drive can be attributed to attainment of a secondary emission coefficient higher than one in multipactor. The threshold value decreases with increase of anode voltage.

The changes near cyclotron resonance have sharply defined features, when ine input drive level is slose to the threshold. These are broadened out as the input drive level increases.

Regions of hysteresis are observed as between the bebavior for a rising value of magnetizing current and a decreasing value of magnetizing current. These could be understood as follows: (a) start of different modes of multipactor at different values of magnetic field, the latter influencing thair transit time, although nnce a given mode gets started it tends to be sustained; (b) the resonance occurs in different regions at different values of focusing current and is accompanied by some release of gases there, presumably due to defocusing effects of the electron beam or due to multipactoring electrons.

Some observations, where corresponding sharp transitions were measured for different values of anode voltage, indicate an increase in the required magnetizing current for the transition with increase in anode voltage. The ratio was in accord with the relativistic change of mass of electrons. 
The magnetic field at the fourth and the fifth cavity and the output region passing through resonanco has a less striking effect on the phenomena observed than if this happens in the region of the first three cavities or the gun region.

The effects of the second harmonic cavity can be correlated with similar effects observed by mechanical tuning. This is indicative of an electronic tuning due to space charge. When the cavity is initially detuned, the space charge tuning can result in either increase or decrease of power output, depending upon the direction oi change from the optimum frequency.

The phenomena are fairly well reproduced from rua tc. run. This is especially true of changes directly attributable to cyclotron resonance.

The variations of residual pressure in the tube as a function of the focus current correlate with variations of power output in two ways. One set of variations closely follows those of the power output for the case of a rising value of the focusing current. This indicates release of gasez mainly in the output region. When the focusing current decreises, the changes in power output are in the opposite sense to the rise in pressure. This is indicative of resonances on the input side of the tube.

It would be worthwhile to carry out further experiments using multiple chanuel recorders which may simultaneously record changes in output power, rise in temperature in the cooling fluid in different sections, residual pressure and pickup from the cavities. These would belp to further pinpoint the origin of the diferent changes as a function oi variations in the magnetic field.

It would also be worthwhile to study the phenomena after coating the inner surfaces of the first three cavities and the drift tubes with very thin layers of titanium or titanium oxide so as to reduce secondary emission and tendency to multipactor. This would tend to reduce the $Q$ of the cavities. However, the effect of that change would probably be less pronounced in the second harmonic cavity than in the case of the 
first twc :avities. The experiment could be first tried out on the second harmonic cavity. This, and a choice of magnetic field profile to stay away from resonances in the more sensitive areas, could raise the threshold drive powel at which the klystrons could operate stably, and also raise the output power available.

\section{Conclusion}

It is seen that in addition to the ratio of the focusing field to the Brillouin field, an important parameter, which has a bearing on the operation of a higb power klystron, is the ratio of the magnetic field to the one corresponding to cyclotron resonance. The effects are more pronounced when these resonances occur either in the gun region or in the first three cavities. In going to higher and higher powars, it would be important to keep these considerations in mind when chuosing the profiles of magnetic fields in different regions of the klystron.

\section{ACKNOWLEDGEMENTS}

The valuable help rendered at various stages of preparation of the manuscript by Ms. Edythe Christianson, Mr. B. S. Gaira and Mr. Ishwar Singh, and in the preparation oi ara:vings by Mr. P. S. Chopra and Mr. Y. N. Gupta, is thankfully acknowledged. 


\section{References}

1. J. F. Gittins, "Power Travelling-Wave Tubes," (English Universities Press 1965), Chap. 4, pp. 86-114.

2. P. J. Tallerico, "Transverse Effects in the High Power Multicavity Klystron," Proc. of the 8th Int. Conf. on Microwave and Optical Generation and Amplifieation, Amsterdam, Netherlands, 1970, pp. 14-1 to 14-6.

3. T. Kageyama, Y. Morizumi and E. Watanabe, "A Large Signal Analysis of Broadband Klystrons with Design Applications," Trans. IEEE, Vol ED-24, January 1977, pp. 98-100.

4. G. B. Collins, Microwave Magnetrons," McGraw Hill Book Co., 1948, pp. $98-100$.

5. M. P. Forrer et al., "Duplexing and Switching with Multipactor Discharges," Proe. I.R.E., April 1962, p. 442.

6. G. T. Konrad, "Performance of a High Efficiency High Power UHF Klystron," presented at the Particle Accelerator Conference, Chicago, Dlinois, March 16-18, 1877.

7. D. H. Priest and R. C. Talcoti, "Heaiing of Output Windows of Microwave Tubes by Electron Bombardment,", Trans. I.R.E., ED-8, 1961, p. 243. 


\section{Figure Captions}

Figure 1 Cross section of the PEP klystron.

Figure 2 Magnetic field along the axis for a current of $20 \mathrm{~A}$, flowing through the coils individually, and all together.

Figure 3 Power output, and rise of temperature of cooling fluid in various sections of the klystron as a function of current through coils number three to ten $\left(I_{\text {mag }}\right) . V_{0}=36 \mathrm{KV}, I_{0}=4.81 \mathrm{~A}, P_{\text {in }}=8.5 \mathrm{~W}$.

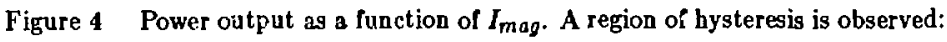
$V_{0}=34 \mathrm{KV}$ and $38 \mathrm{KV}, P_{\text {in }}=7.1 \mathrm{~W}$.

Figure 5 Power output and pickup from second harmonic cavity as functions of $I_{\text {mag. }} V_{0}=38 \mathrm{KV}, P_{\text {in }}=8.4 \mathrm{~W}$.

Figure 6 Performance of PEP-2 Klystron as a function of second harmonic cavity tuning $\left(V_{0}=38 \mathrm{KV}\right.$, fo $\left.=353.2 \mathrm{MHz}\right)$.

Figure 7 Pickup from probes in cavities number one to four as functions of $I_{\text {mag }}, V_{0}=32 \mathrm{KV}, P_{\text {in }}=8.5 \mathrm{~W}$.

Figure 8 Power output as a function of $I_{\text {mag }}$, with second harmonic cavity retuned to $696.508 \mathrm{MHz} . V_{0}$ at $34 \mathrm{KV}, 36 \mathrm{KV}$ and $38 \mathrm{KV}$, and $P_{\text {in }}=8.5 \mathrm{~W}$.

Figure 8 Power output as a function of $I_{m a g}$, with second harmonic cavity retuned to $708.182 \mathrm{MHz}$. $V_{0}$ at $32 \mathrm{KV}, 36 \mathrm{KV}$ and $38 \mathrm{KV}$, and $P_{\text {in }}=8.5 \mathrm{~W}$. 
Figure 10 Power output versus $I_{\text {mag }}$ curves for different input drive power levels, indicating sharp threshold effecis.

Figure 11 Variation of threshold for input drive pciwer level us function of anode voltage.

Figure 12 Power output as a function of $I_{m a g}$ just at the input power threshold of instability. $V_{0}=45 \mathrm{KV}, P_{\text {in }}=5.7 \mathrm{~W}$.

Figrire 13 Two sets of curves of power output as a function of $I_{\text {mag }}$ at threshold of input power as a check on reproducibility. $V_{0}$ at higher value of $57 \mathrm{KV}, P_{\text {in }}=5.2 \mathrm{~W}$.

Figure 14 Power output as a function of $I_{\operatorname{mag}}$ at higher values of input drive, viz., $10 \mathrm{~W}, 15 \mathrm{~W}, 20 \mathrm{~W}$ and $24 \mathrm{~W}$. $V_{0}=45 \mathrm{KV}$.

Figure 15 Power output as a function of current in coils number seven to ten (towards output side). $V_{\mathfrak{g}}=50 \mathrm{KV}$; surrent in coils uumber three to six is $20 \mathrm{~A}$.

Figure 16 Power output as a function of current in coils number four, five and six (near second harmonic cavity); current in coil number three is $15 \mathrm{~A}$ and that in coils number four to ten is $20 \mathrm{~A}$.

Figure 17 Power output as a function of current in coils number three (near input cavity). Current in coils number one and two is $17 \mathrm{~A}$. Current in coils number four to ten is $20 \mathrm{~A}_{i} V_{0}=55 \mathrm{KV}$.

Figure 18 Comparison of power output and residual pressure as a function of $I_{\text {mag }}$ (current in coils number three to ten); $V_{0}=50 \mathrm{KV}, P_{\text {in }}=12 \mathrm{~W}$. 
Figure 19 Comparison of power output and residual pressure as functions of $I_{\text {mug }} ; V_{0}=60 \mathrm{KV}, P_{\text {in }}=10 \mathrm{~W}$.

Figure 20 Frequency spectra and if envelopes near instability points. $V_{0}=40 \mathrm{KV}$.
(a) $I_{m a g}=18.4 \mathrm{~A}$ and $P_{\text {in }}=8.5 \mathrm{~W}$ (frequency spectrum).
(b) $I_{m a g}=16.5 \mathrm{~A}$ and $P_{i n}=20 \mathrm{~W}$ (frequency spectrum).
(c) $I_{m a g}=16.5 \mathrm{~A}$ and $P_{\text {in }}=20 \mathrm{~W}$ ( $r$ envelope).
(d) $I_{m a g}=17.7 \mathrm{~A}$ and $P_{i n}=20 \mathrm{~W}$ (frequency spectrum).
(e) $I_{m a g}=17.7 \mathrm{~A}$ and $P_{\text {in }}=20 \mathrm{~W}$ (rf envelope).

Figure 21 (a) Frequency spectrum for $I_{m a g}=22.6 \mathrm{~A}_{i} P_{i n}=24 \mathrm{~W}$.

(b) If envelope for $I_{\text {mag }}=22.6 \mathrm{~A} ; P_{\text {in }}=24 \mathrm{~W}$.

(c) A repeat of (b) at a little later time.

(d) Relaxation oscillation shown in if envelope for

$$
I_{m a g}=16.5 \mathrm{~A} ; P_{i n}=24 \mathrm{~W} \text {. }
$$




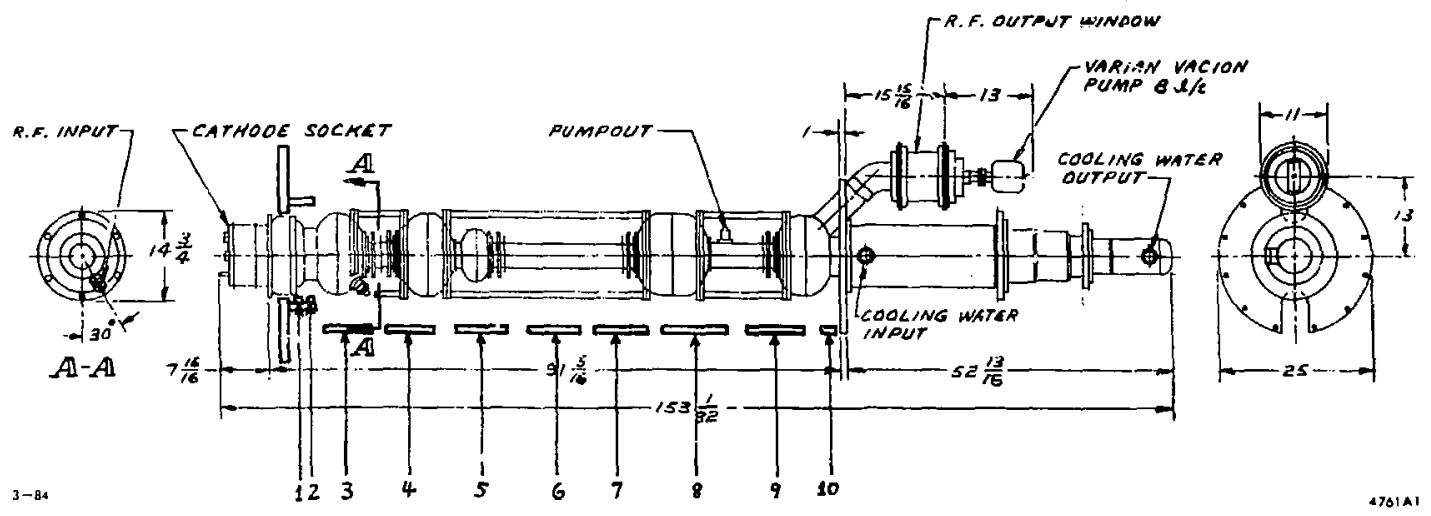

Fig. 1 


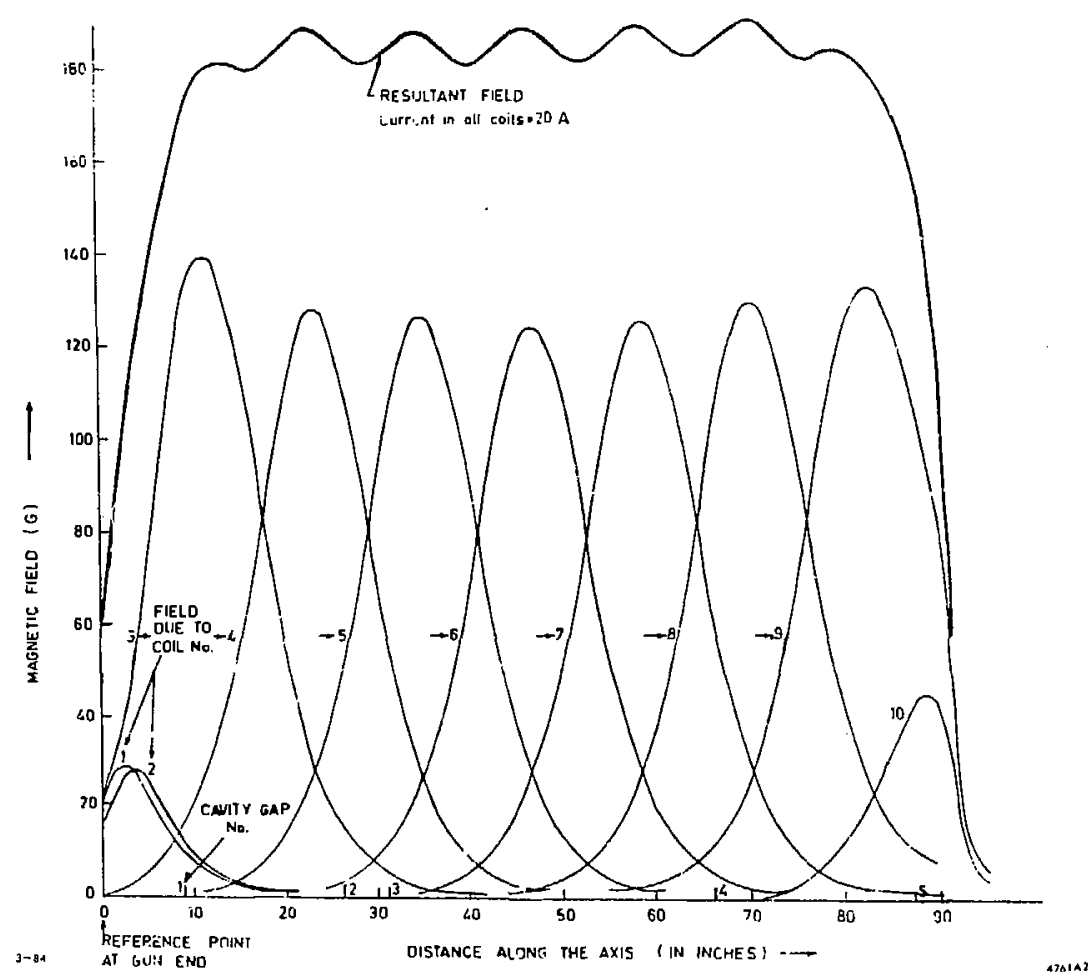

Fig. 2 


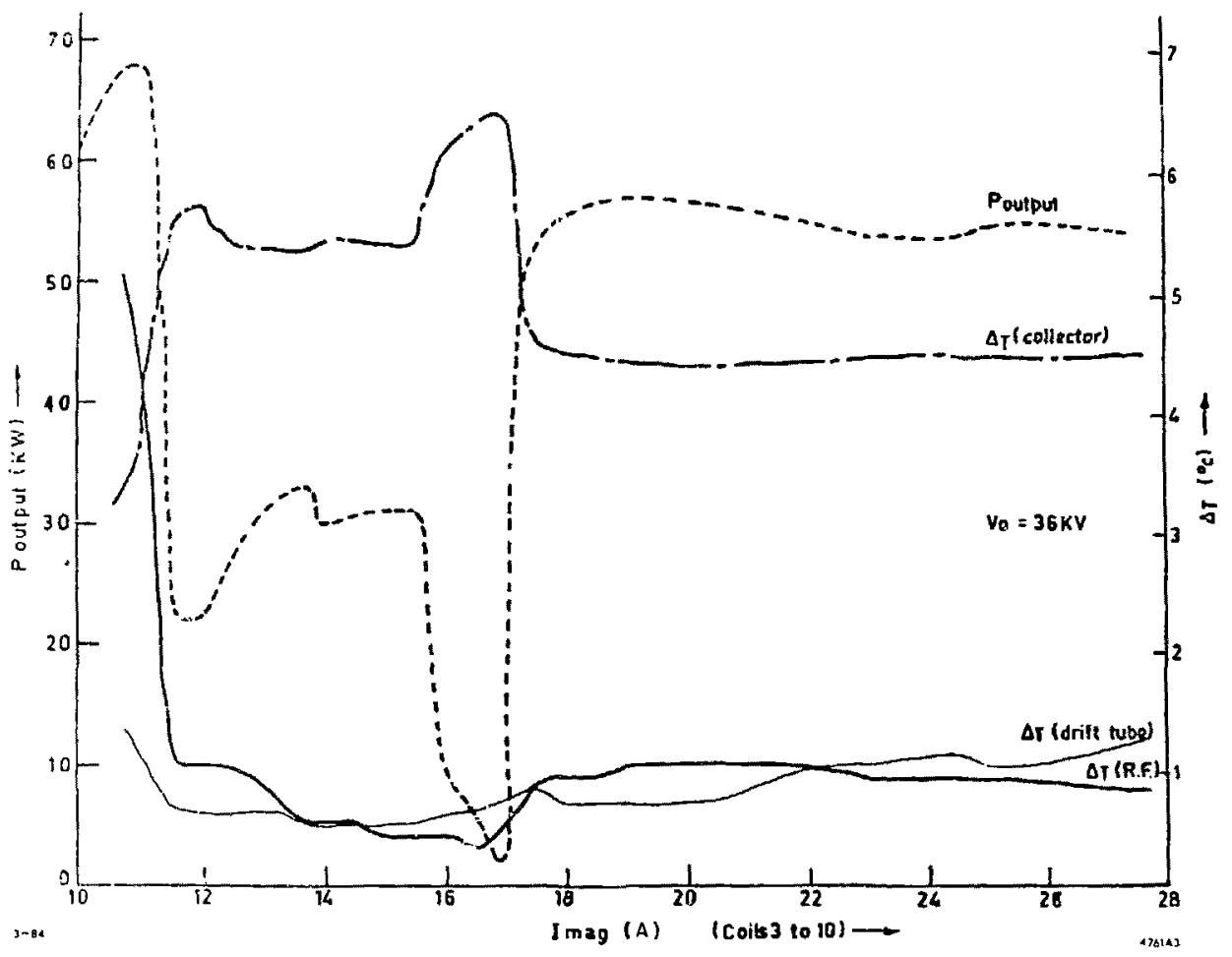

Fig. 3 


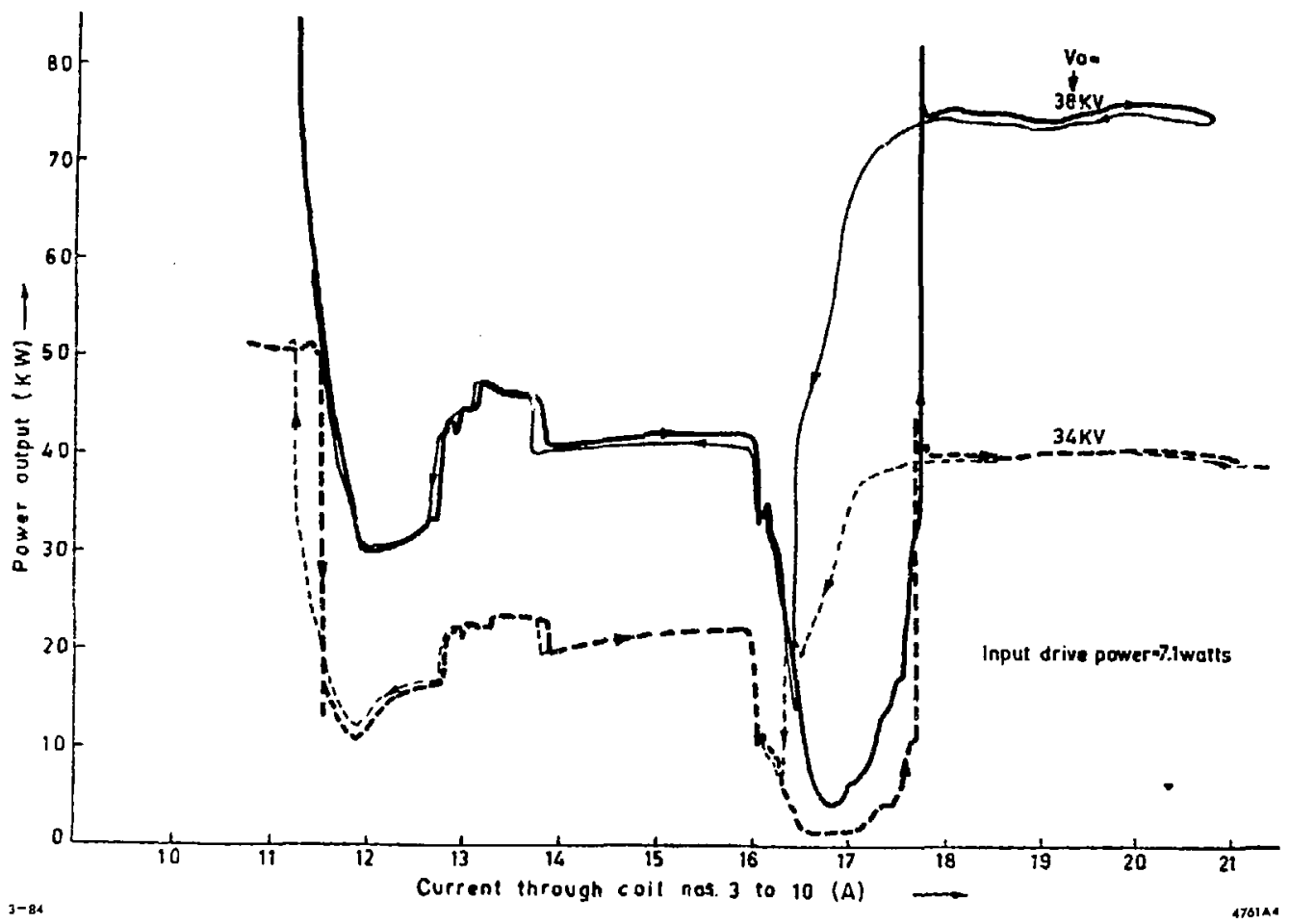

Fig. 4 


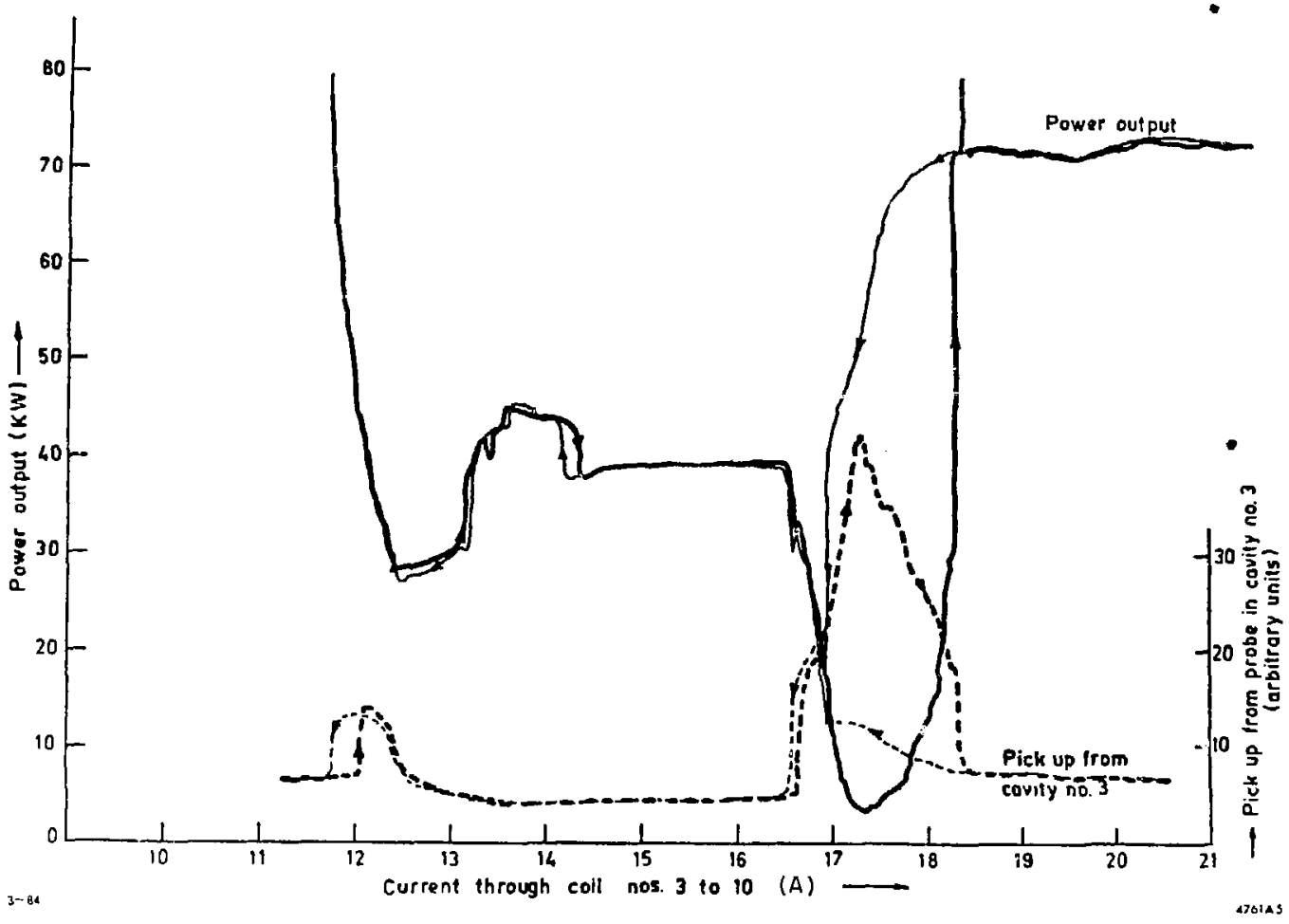

Fig. 5 


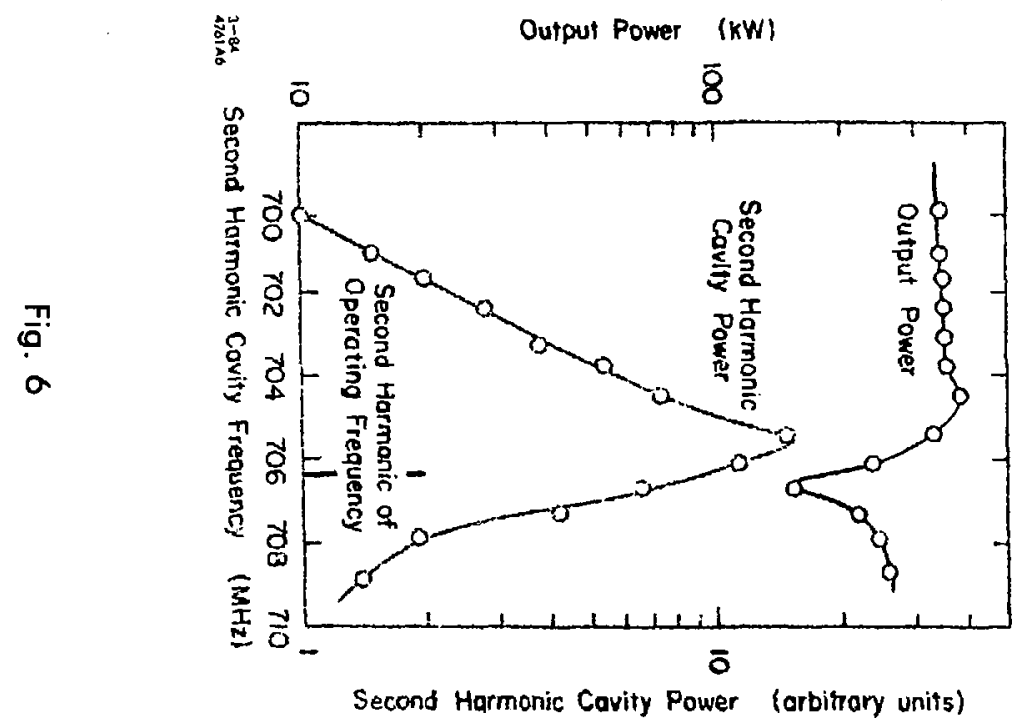




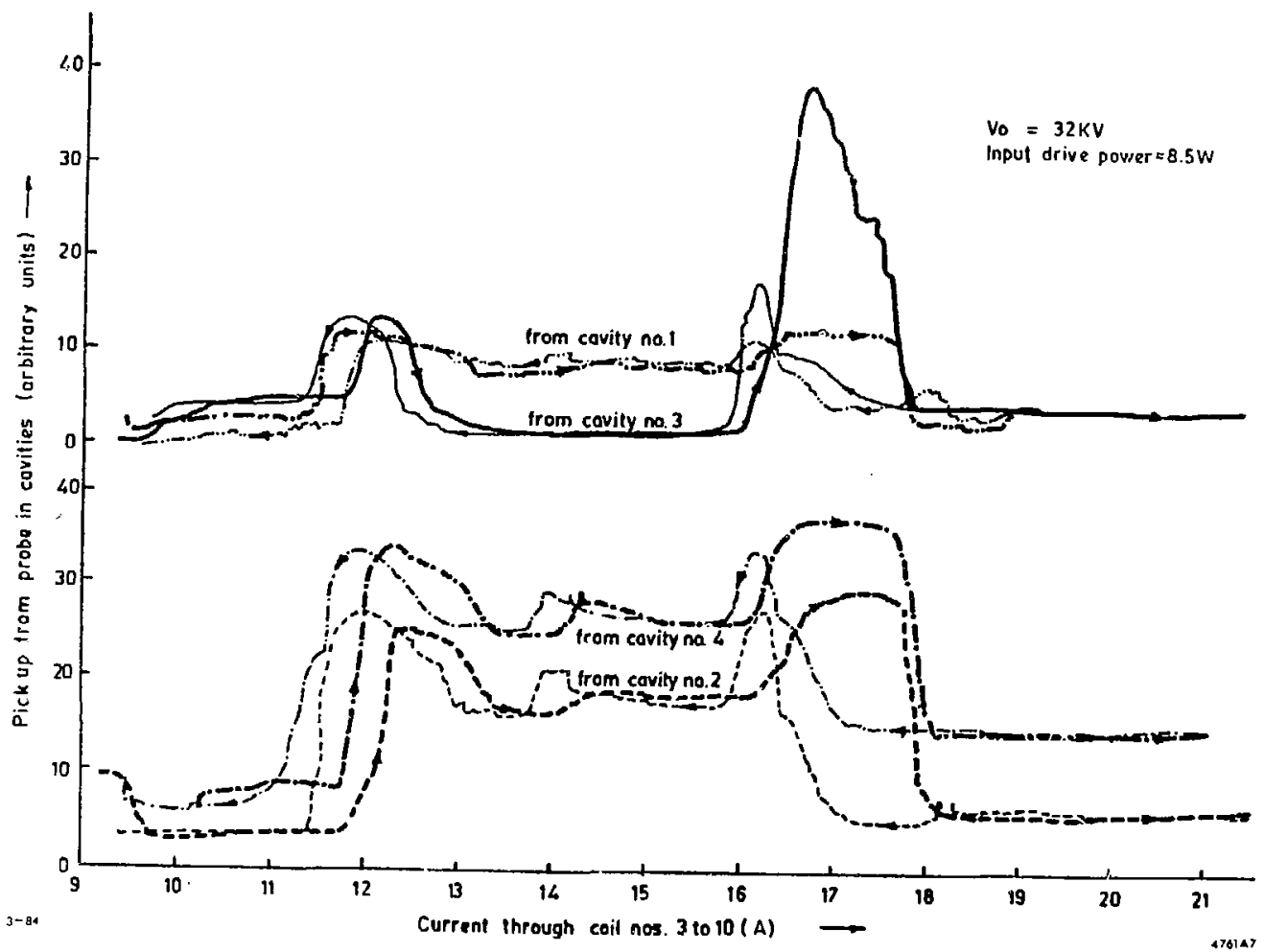

Fig. 7 


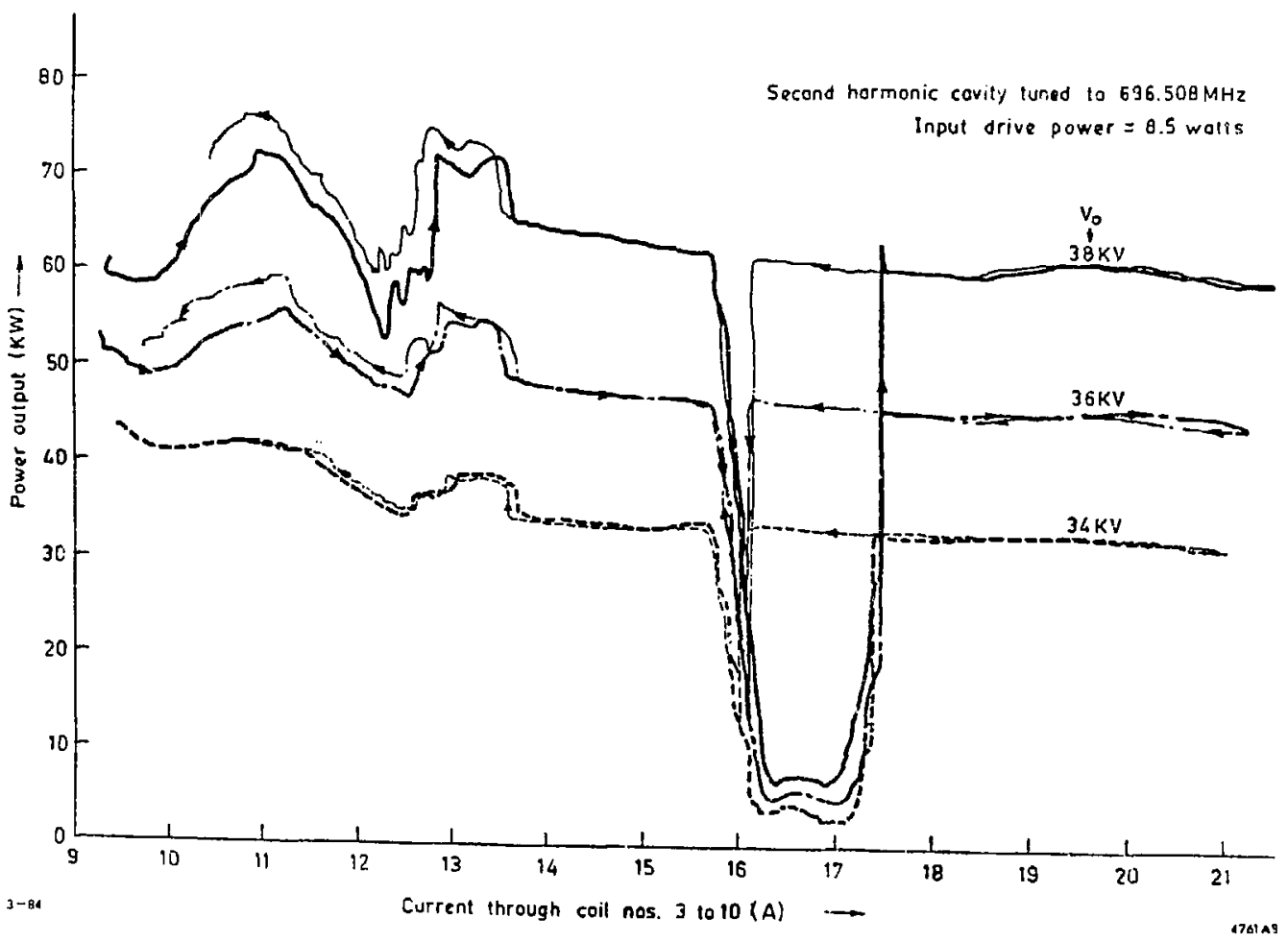

Fig. 8 



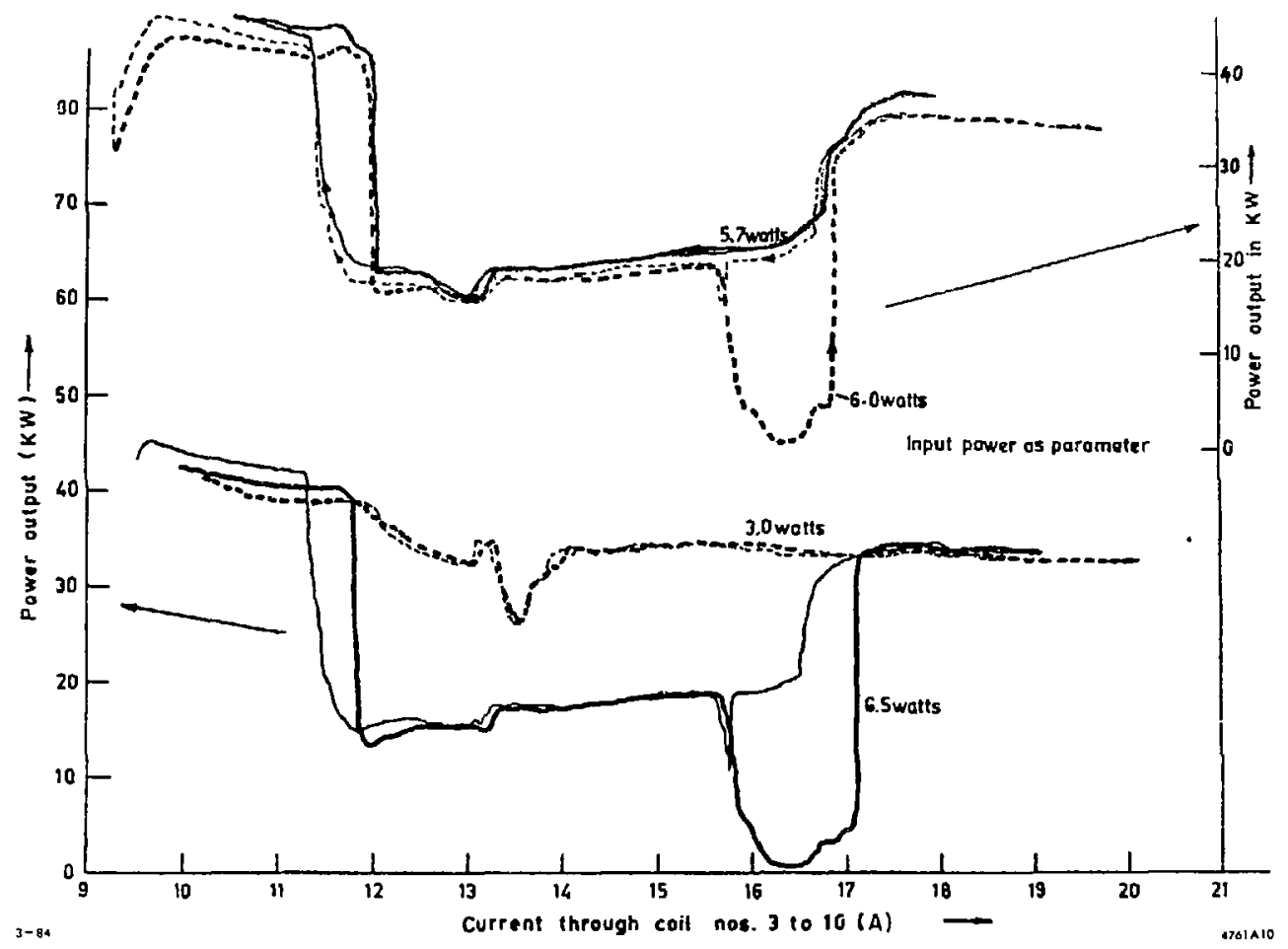

Fig. 10 


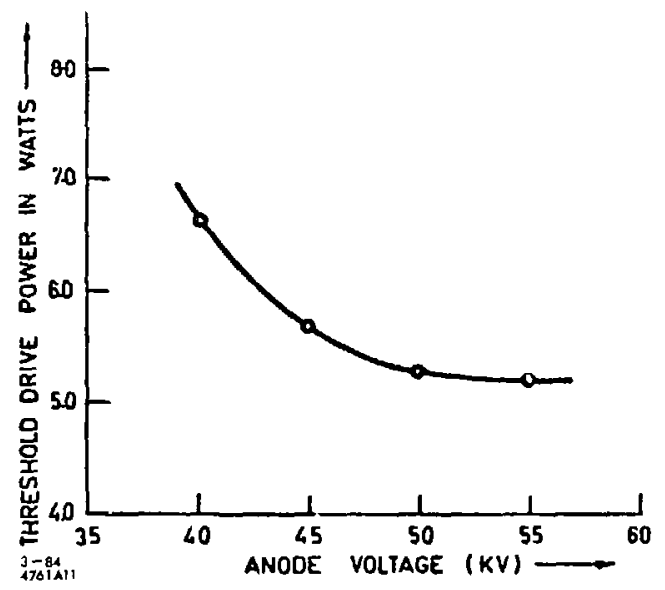

Fig. 11 


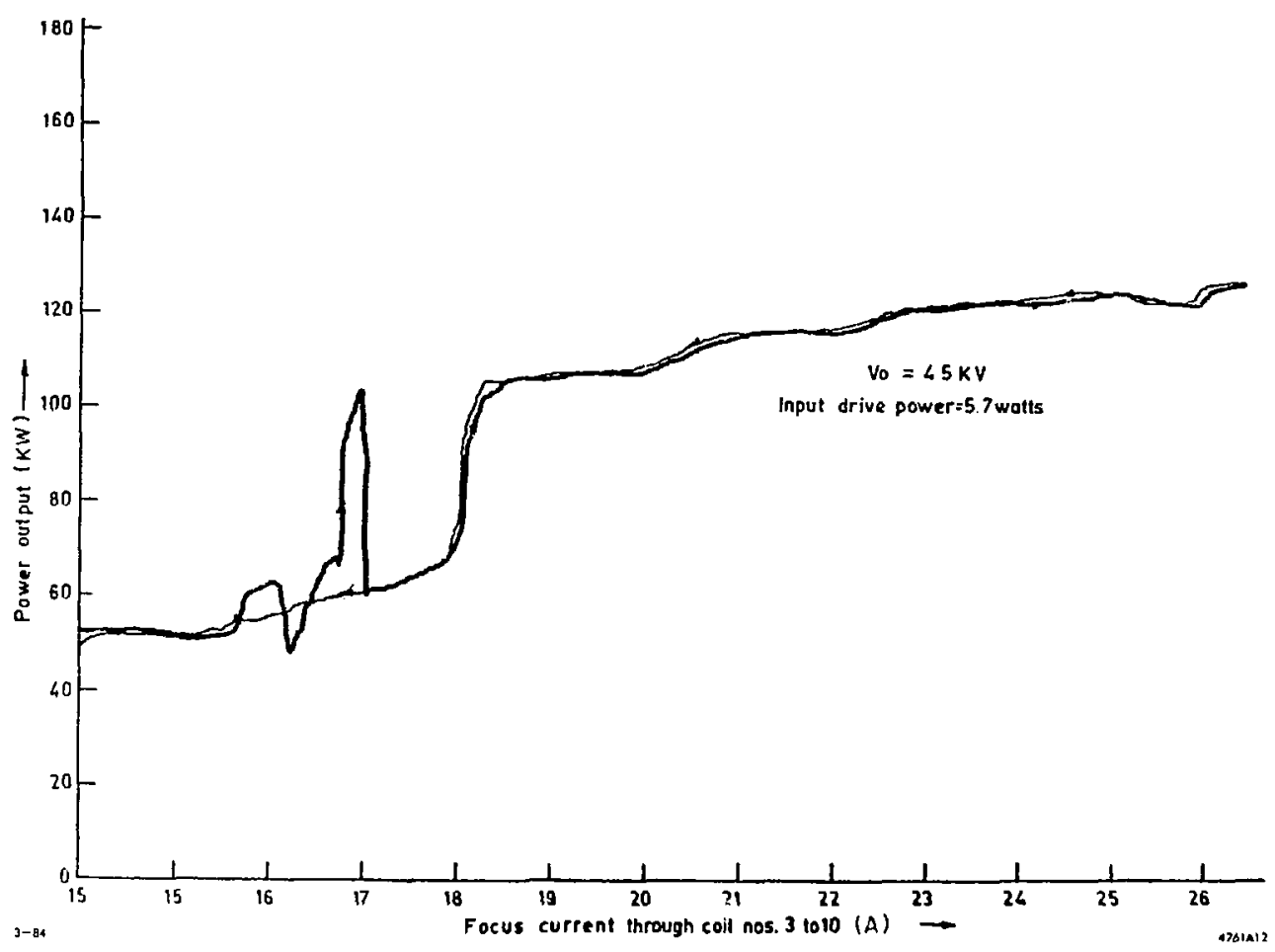

Fig. 12 


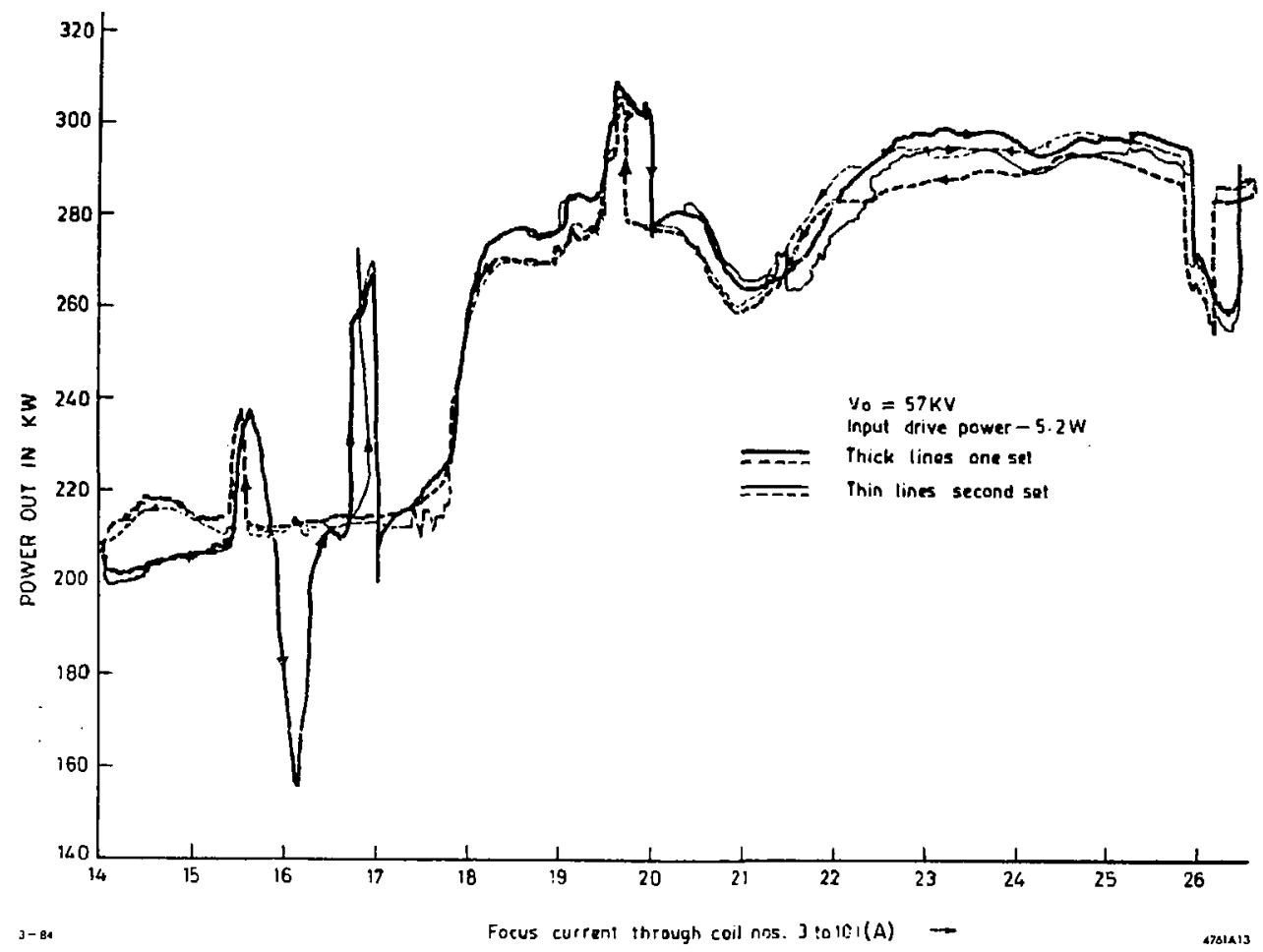

Fig. 13 


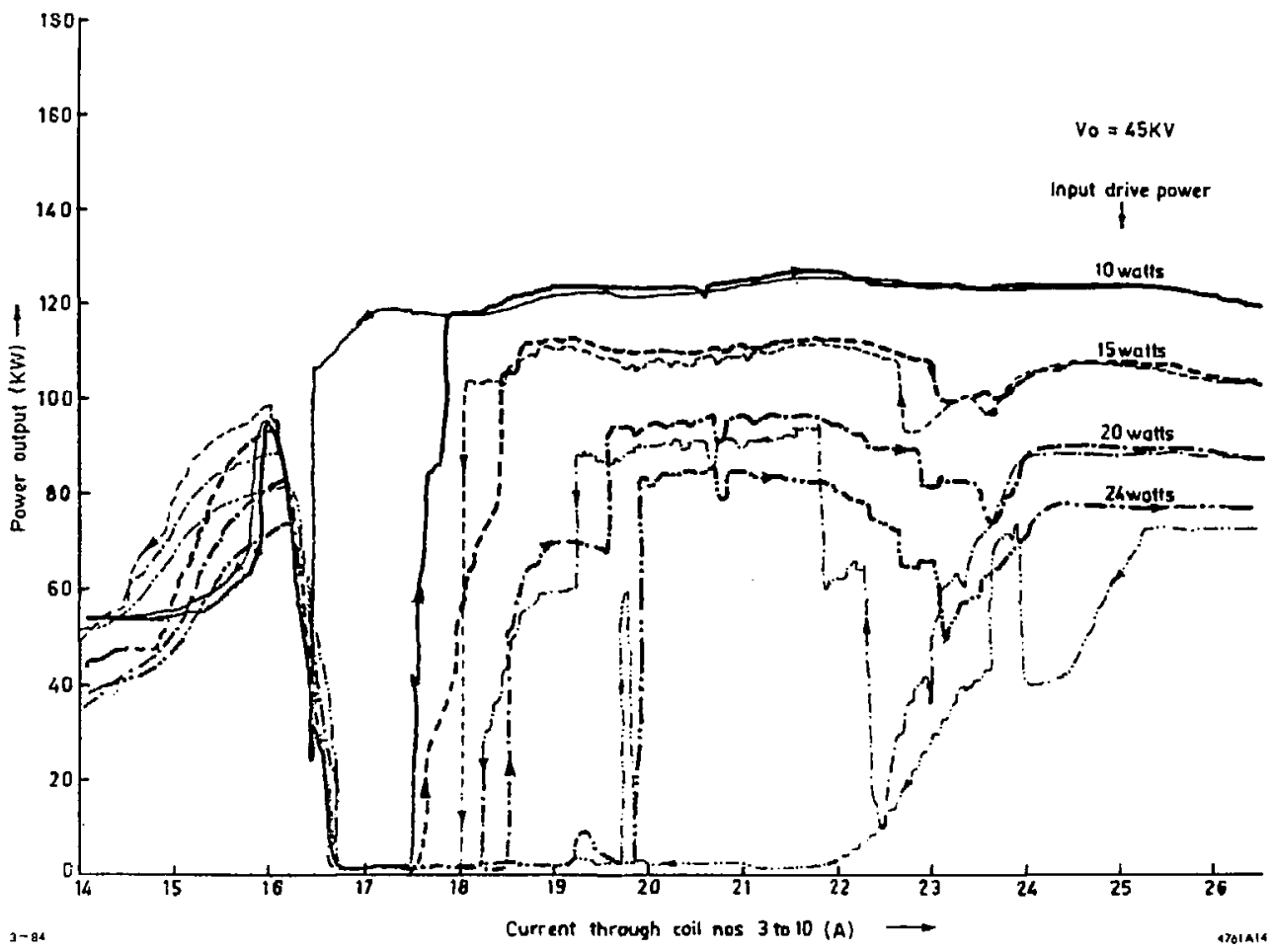

Fig. 14 


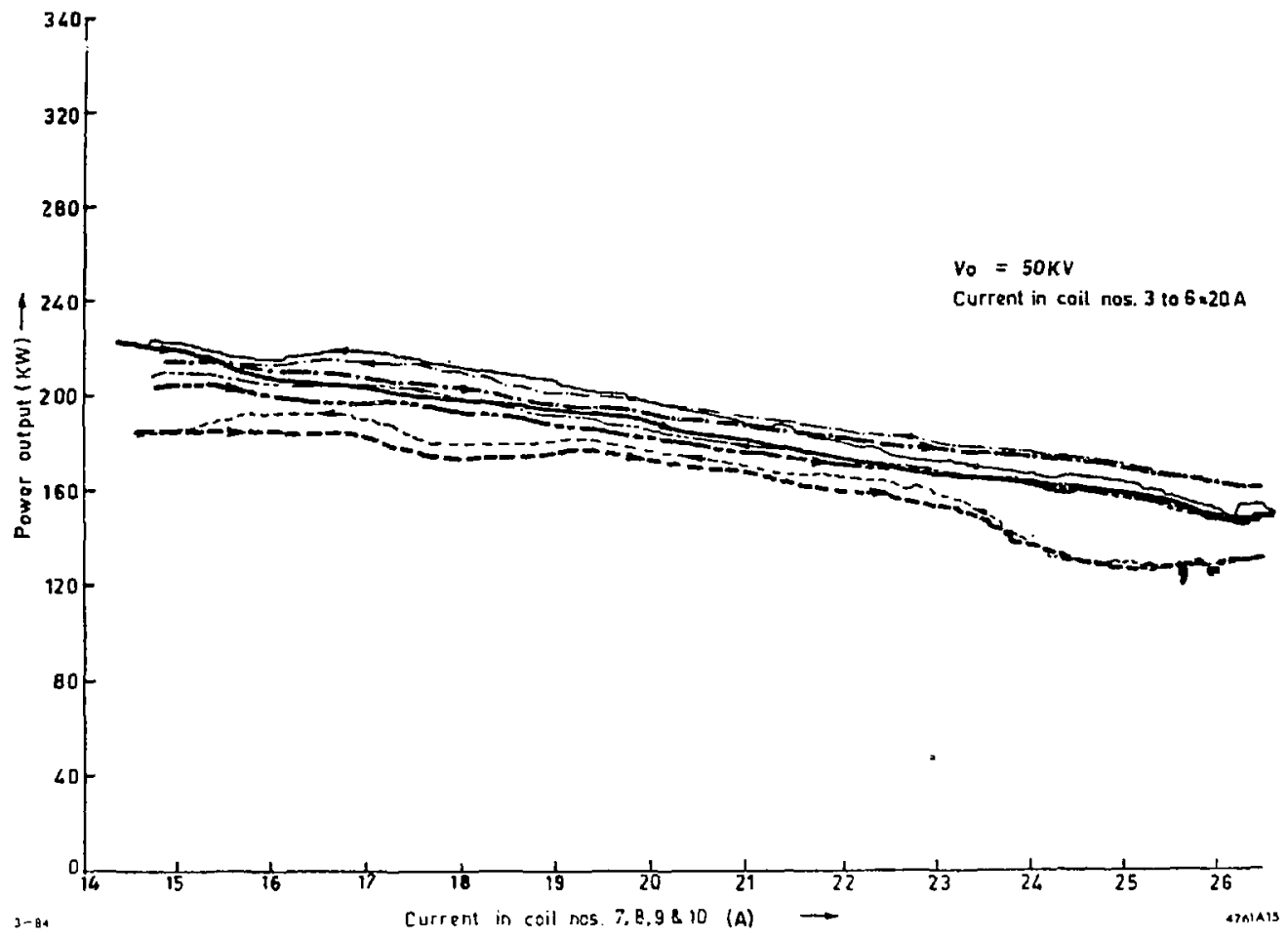

Fig. 15 


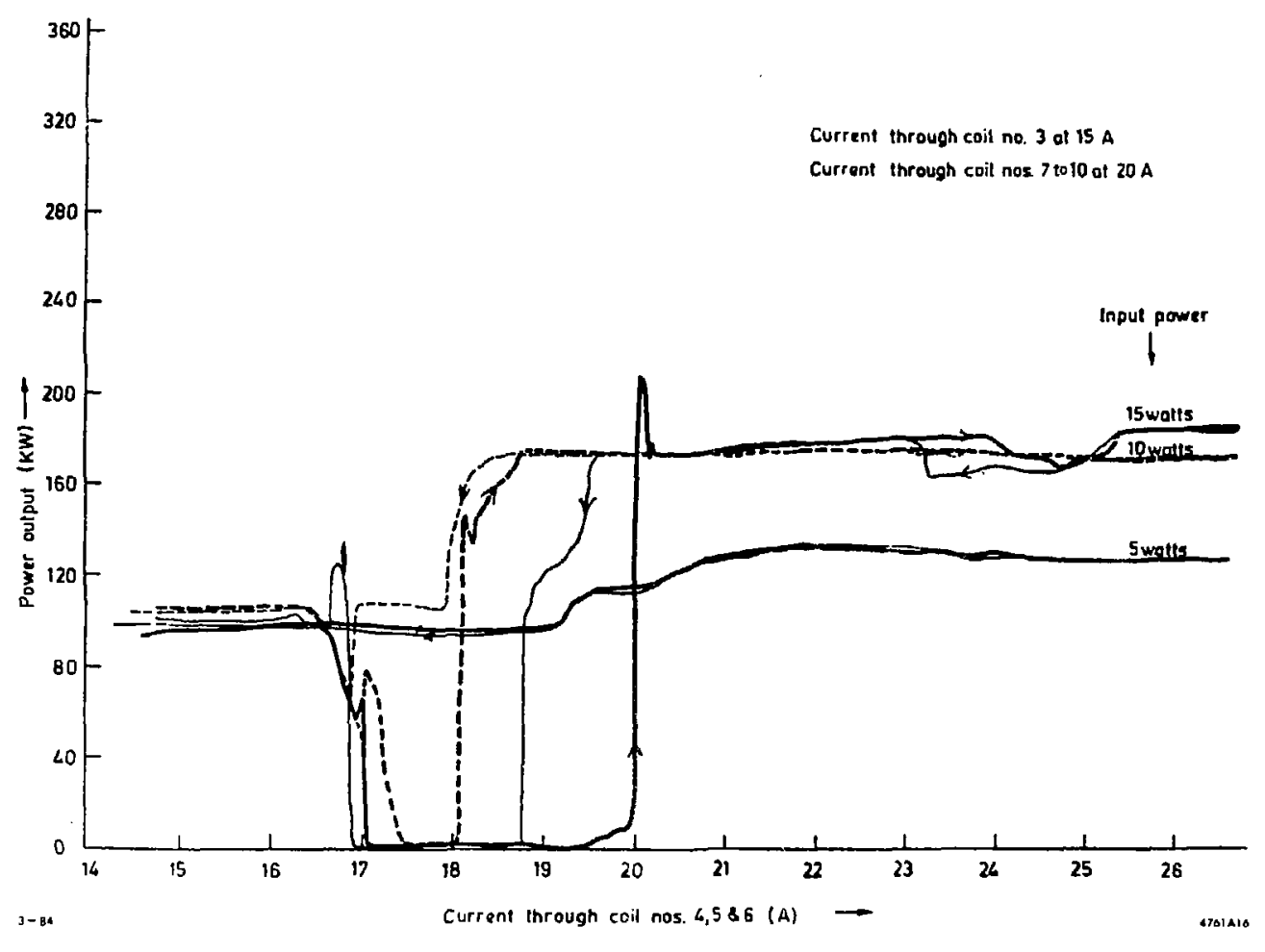

Fig. 16 


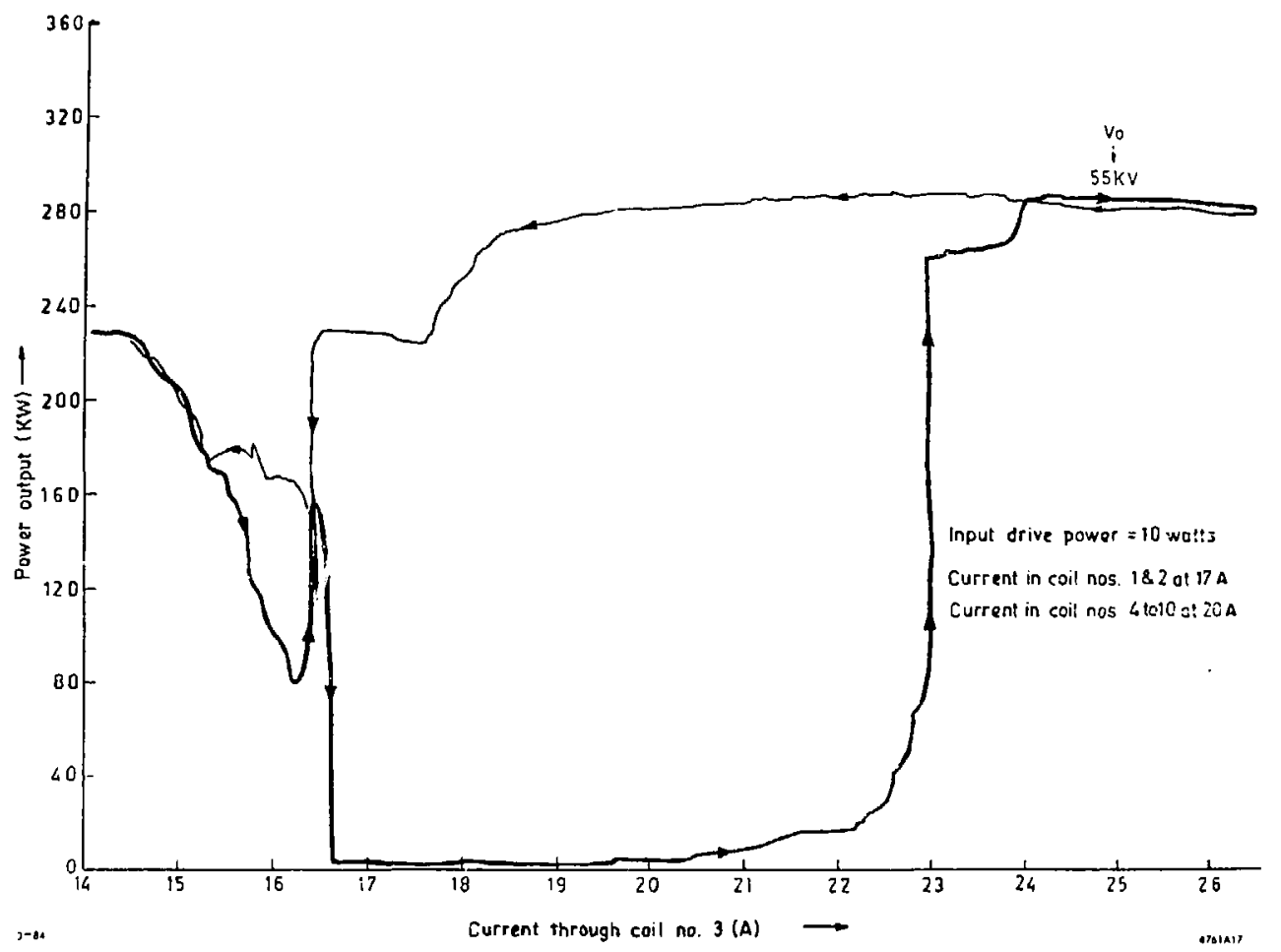

Fig. 17 


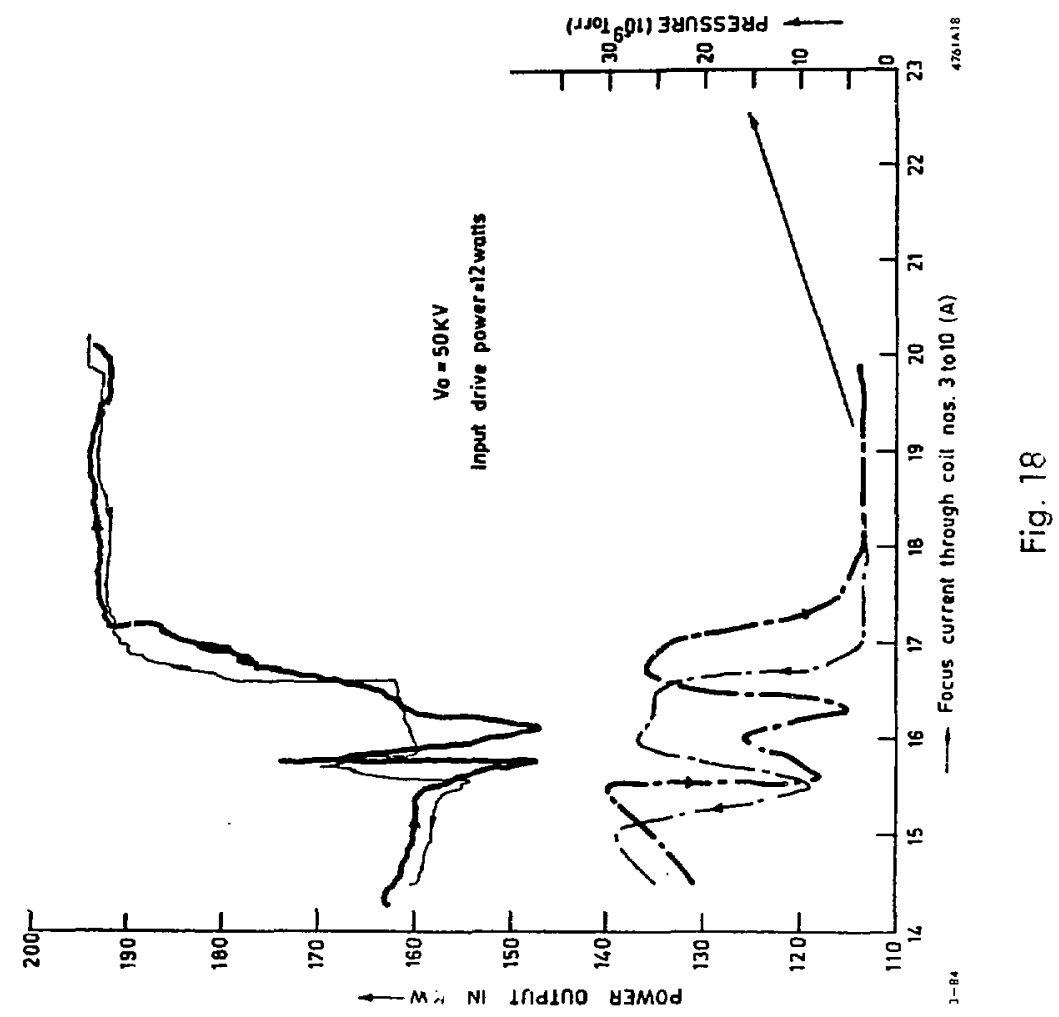




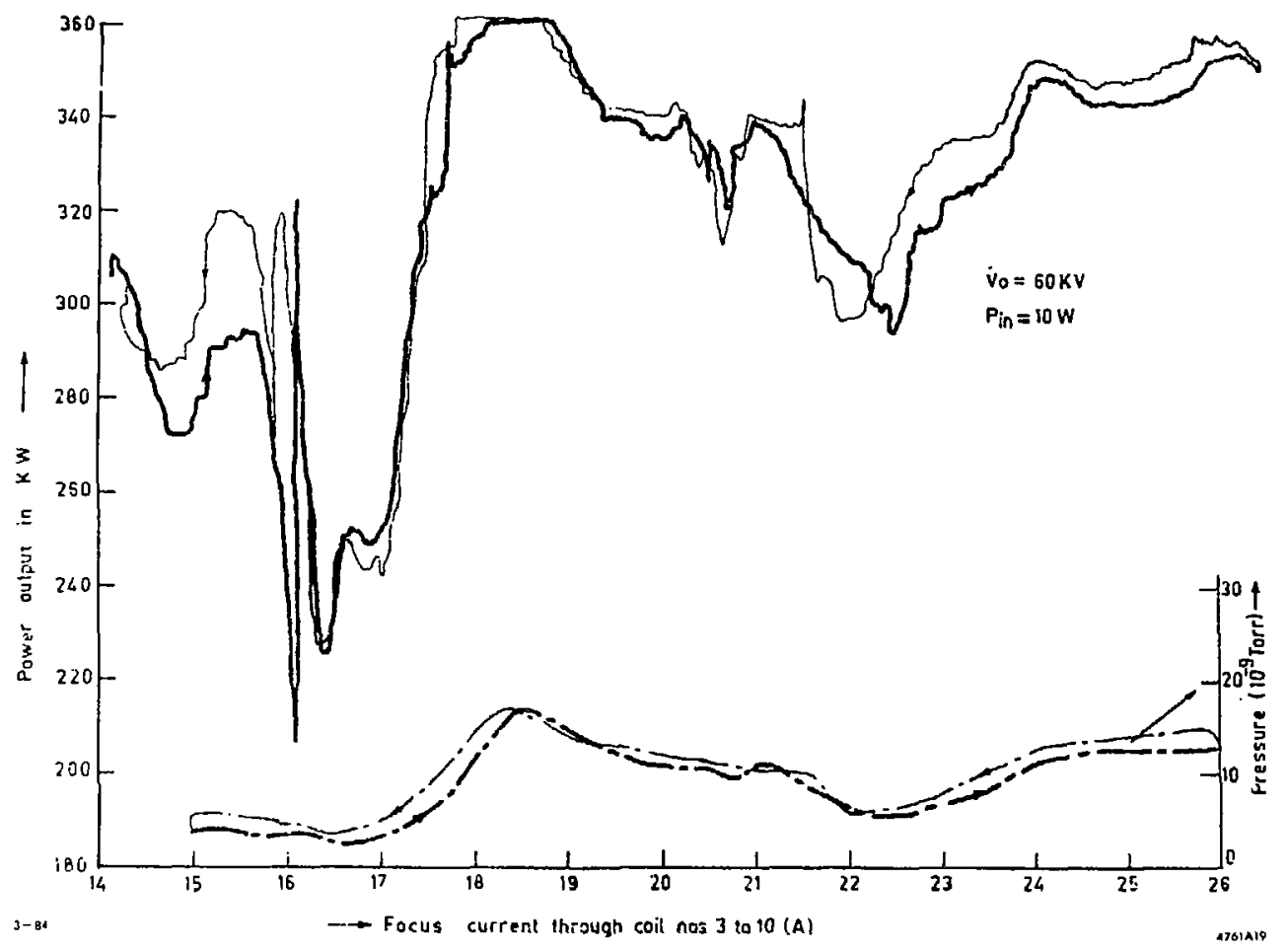

Fig. 19 


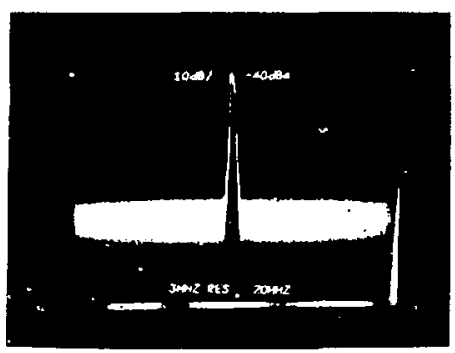

(a)
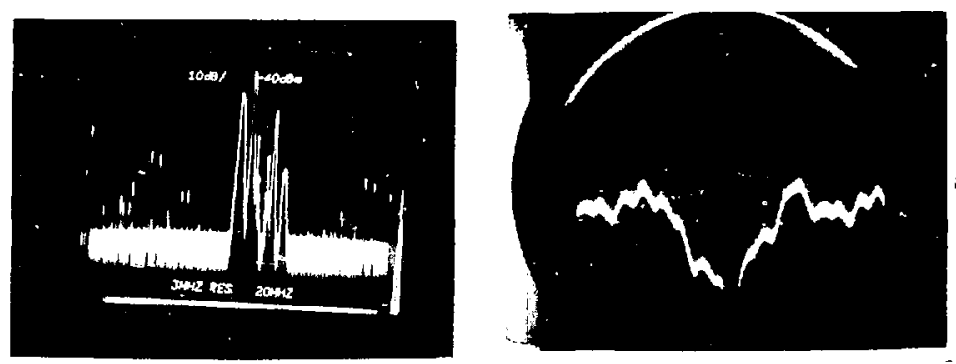

(b)

(c)

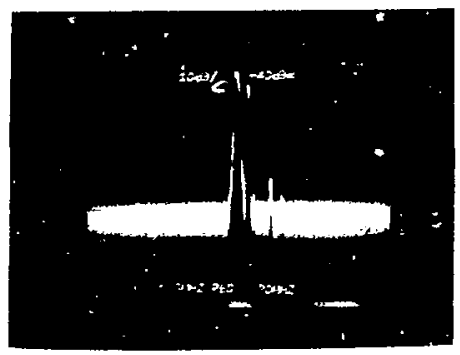

(d)

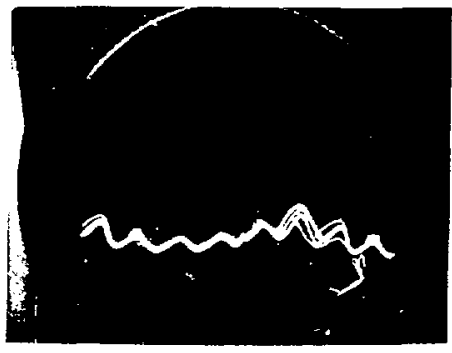

(e)

$\begin{array}{r}3-84 \\ 4761 A 20\end{array}$

Fig. 20 


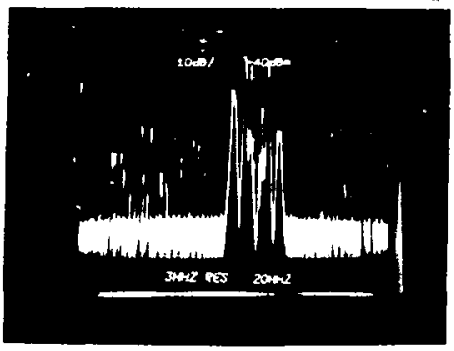

(a)

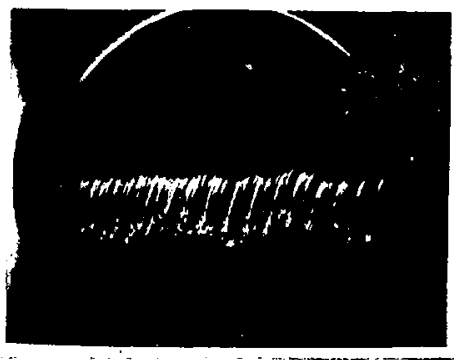

(b)

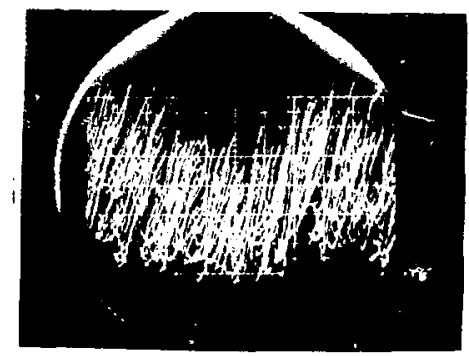

\section{(c)}

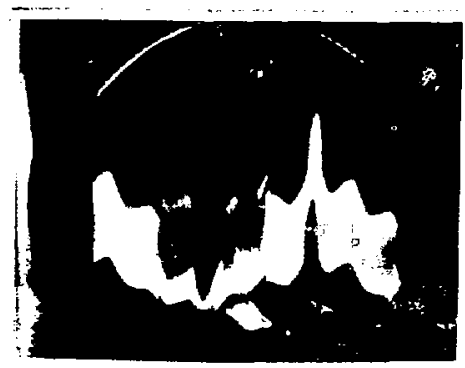

3-84

(d)

Fig. 21 